\title{
Severidade de doenças foliares em mudas de cebola produzidas em túnel baixo
}

\author{
Leandro Luiz Marcuzzo ${ }^{1}$, Maíra Rodrigues Duffeck ${ }^{1}$, Roberto Haveroth ${ }^{1}$, Katiani Eli ${ }^{1}$, \\ Régis Carlos Teodoro Nunes ${ }^{1}$, Jaqueline Carvalho ${ }^{1}$, Robinson Jardel Pires de Oliveira ${ }^{1}$
}

${ }^{1}$ Instituto Federal Catarinense - IFC/Campus Rio do Sul, CP 441, CEP 89.163-356, Rio do Sul, SC, Brasil
Autor para correspondência: Leandro Luiz Marcuzzo (leandro.marcuzzo@ifc.edu.br)
Data de chegada: 06/09/2016. Aceito para publicação em: 12/04/2017.

$10.1590 / 0100-5405 / 168902$

\section{RESUMO}

Marcuzzo, L.L.; Duffeck, M.R.; Haveroth, R.; Eli, K.; Nunes, R.C.T.; Carvalho, J.; Oliveira, R.J.P. Severidade de doenças foliares em mudas de cebola produzidas em túnel baixo. Summa Phytopathologica, v.44, n.4, p.391-393, 2018.

A produção de mudas de cebola na região do Alto Vale do Itajaí, SC ocorre predominantemente através de canteiros, onde as plantas ficam expostas aos fatores bióticos e abióticos que influenciam diretamente na sanidade foliar e no seu rendimento. Diante disso, o objetivo deste trabalho foi avaliar a influência da cobertura dos canteiros com túnel baixo sobre o rendimento e a intensidade de doenças foliares. Os experimentos foram realizados nos anos de 2012 e 2013 no Instituto Federal Catarinense, Campus de Rio do Sul, SC. Os tratamentos foram com e sem o uso de túnel baixo. O delineamento utilizado foi o de blocos casualizados com quatro repetições e dez plantas avaliadas em cada repetição. Os dados foram submetidos à análise de variância pelo teste $\mathrm{F}$ e se significativos comparados pelo teste de Tukey 5\%. A massa fresca da parte aérea com o uso do túnel foram superiores em relação ao sistema convencional em $127,38 \%$ e $125,40 \%$ no ano de 2012 e 2013 respectivamente. Em 2012 ocorreu uma diferença de $42,88 \%$ na área abaixo da curva de progresso da doença (AACPD) da queima das pontas e no ano de 2013 uma diferença de $87,27 \%$ e $85 \%$ na AACPD e severidade final respectivamente para o míldio. As mudas produzidas em canteiros com túnel baixo apresentaram superioridade no rendimento e sanidade foliar em relação às obtidas no sistema de produção convencional.

Palavras-chave: Allium cepa, cobertura plástica, produtividade, sanidade foliar.

\section{ABSTRACT}

Marcuzzo, L.L.; Duffeck, M.R.; Haveroth, R.; Eli, K.; Nunes, R.C.T.; Carvalho, J.; Oliveira, R.J.P. Severity of leaf diseases in onion seedlings produced in low tunnel. Summa Phytopathologica, v.44, n.4, p.391-393, 2018.

Production of onion seedlings at the region of Alto Vale do Itajaí, Santa Catarina State (SC), Brazil, occurs predominantly in seedbeds, where the plants are exposed to biotic and abiotic factors that directly influence the leaf health and the yield. Thus, the aim of this study was to evaluate the influence of covering seedbeds with low tunnel system on the yield and intensity of leaf diseases. The experiments were carried out in 2012 and 2013 at "Instituto Federal Catarinense", Rio do Sul, SC. The treatments were with and without low tunnel system. Experimental design was in randomized blocks with four replicates and ten plants evaluated in each replicate. Data were subjected to analysis of variance by the F test and if significant compared according to Tukey's test $5 \%$. The fresh weight of the aerial part with the tunnel was superior to the conventional system by $127.38 \%$ and $125.40 \%$ in 2012 and 2013, respectively. In 2012, there was a difference of $42.88 \%$ in the area under the disease progress curve (AUDPC) for leaf blight and in 2013 there was a difference of $87.27 \%$ and $85 \%$ in the AUDPC and final severity, respectively, for downy mildew. The seedlings grown in seedbeds with low tunnel system had superior yield and leaf health, compared to those obtained in the conventional production system.

Keywords: Allium cepa, plastic cover, yield, leaf sanity.

A cultura da cebola (Allium cepa) ocupa o terceiro lugar entre as hortaliças de maior expressão econômica do Brasil e constitui atividade socioeconômica de grande relevância para pequenos produtores da região sul.

A implantação do cultivo da cebola pode ser estabelecida pela semeadura direta, por "bulbinhos", mudas produzidas em bandejas ou mudas de raízes nuas obtidas em sementeira. A produção de mudas em canteiro e/ou sementeira tem como consequência à exposição constante das plantas a fatores abióticos e bióticos que influenciam diretamente aspectos produtivos e fitossanitários. No sistema de plantio por mudas o sucesso na produção de bulbos depende diretamente da qualidade da muda obtida na sementeira, já que o seu desenvolvimento inicial é fundamental para a obtenção de um bom estande por ocasião do transplante (6).

No estado de Santa Catarina, na região do Alto Vale do Itajaí (AVI) ocorre o predomínio do sistema de produção de mudas em canteiro e as condições climáticas durante a fase de canteiro são caracterizadas por temperaturas amenas e alta umidade, propiciando a infecção concomitante de Botrytis squamosa Walker, agente causal da queima das pontas e de Peronospora destructor Berk. (Casp.), causador do míldio, os quais influenciam diretamente a produção e a qualidade das mudas $(1,2)$.

A cobertura plástica do canteiro pode ser uma alternativa para diminuir os impactos diretos das intempéries climáticas sobre a 
produção da muda e também a intensidade de doenças. Diante do exposto, este trabalho teve por objetivo avaliar o rendimento e a severidade de doenças foliares na produção de mudas de cebola sob túnel baixo nas condições da região do AVI, SC.

O experimento foi realizado nos anos de 2012 e 2013 (semeadura em 15 de abril e colheita em 30 de junho), no setor de Horticultura do Instituto Federal Catarinense - Campus de Rio do Sul, município de Rio do Sul/SC com latitude sul de $27^{\circ} 11^{\prime} 07^{\prime}$, longitude oeste de 49³9'39" e altitude de 687 metros do nível do mar.

Os tratamentos consistiram na produção de mudas de cebola em canteiros com e sem o uso de túnel baixo. O delineamento experimental utilizado foi em blocos casualizados com quatro repetições. Cada repetição consistia em canteiro de 3,0 m de comprimento X 1,20 m de largura e altura do canteiro de $0,15 \mathrm{~m}$. A avaliação das doenças e aspectos produtivos foi realizada em 10 plantas demarcadas aleatoriamente dentro de cada repetição.

A semeadura de cebola da cultivar Bola Precoce, predominante na região do AVI foi realizada a lanço com $3 \mathrm{~g}$ de semente por $\mathrm{m}^{2}$ e cobertas com $1 \mathrm{~cm}$ de pó de serra durante a segunda quinzena do mês de abril. As plantas espontâneas que surgiam eram retiradas manualmente e não se constatou a presença de insetos devido à época de cultivo.

No tratamento em túnel baixo foi utilizada estrutura metálica em arco galvanizado liso $\mathrm{n}^{\circ} 6(5,15 \mathrm{~mm}$ de diâmetro) com 1,20 $\mathrm{m}$ de largura e altura do solo de $0,6 \mathrm{~m}$, com distância entre arcos de $1,50 \mathrm{~m}$. O túnel foi coberto com filme de polietileno transparente de 120 micras. O manejo da ventilação dos túneis foi realizado conforme as condições meteorológicas do dia, abertos de dia e mantidos fechados a noite, sendo que dias com neblina e/ou chuva foram mantidos fechados. A irrigação foi feita por três linhas de tubos gotejadores colocados entre as fileiras laterais e centrais na extensão de cada canteiro.

Semanalmente as plantas foram analisadas quanto á presença de sintomas de doenças. A confirmação dos sintomas, quando necessária, foi realizada no Laboratório de Fitopatologia do IFC Rio do Sul, $\mathrm{SC}$, com o uso de microscópio estereoscópico para visualização de estruturas dos fungos presentes nas plantas e posteriormente foi realizada quantificação da severidade. A severidade das doenças foi analisada visualmente através da porcentagem de área foliar afetada pela doença em cada folha exposta. Os valores de severidade foram integralizados e calculados pela área abaixo da curva de progresso da doença (AACPD) e juntamente com a severidade final foram utilizados para comparar a intensidade de doenças entre tratamentos.

$\mathrm{O}$ peso da massa fresca da parte aérea $(\mathrm{g})$ foi avaliado aos 60 dias após a semeadura e juntamente com os valores médios da AACPD e severidade final foram submetidos à análise de variância e as médias comparadas pelo teste F 5\% pelo software estatístico SASM-Agri (3).

A massa fresca da parte aérea (Tabela 1) foi influenciada pelo uso da cobertura plástica do canteiro, uma vez que apresentou maior incremento em relação aos canteiros descobertos. A variável massa fresca da parte aérea em plantas sob o túnel baixo apresentou um incremento de $127,38 \%$ e $125,40 \%$, respectivamente nos anos de 2012 e 2013 (Tabela 1).

A superioridade da cobertura do canteiro com túnel plástico em relação ao ambiente natural concorda com os resultados obtidos por Sá \& Reghin (7). Estes autores observaram em experimento com chicória $23,4 \%$ de acréscimo na massa fresca com o uso de túnel em relação ao ambiente natural. Streck et al. (9) verificaram em alface em cultivo de inverno com utilização de cobertura dos canteiros um incremento de $136,66 \%$ para a massa da matéria fresca quando comparado com a ausência de cobertura.

Em relação a doenças foliares foi verificada a ocorrência de duas doenças de grande importância para a cultura da cebola na região do AVI. Porém, cada doença teve sua ocorrência verificada em anos distintos de avaliação, possivelmente decorrente das condições de infecção natural e do inóculo presente no ambiente, já que no mesmo local do experimento foi cultivado cebolinha-verde.

A queima das pontas causada por B. squamosa é a doença de maior frequência em canteiros para produção de mudas de cebola no AVI (2), sendo que a mesma foi diagnosticada nos dois tratamentos no ano de 2012. No entanto a AACPD foi reduzida em $42,88 \%$ com a cobertura do canteiro e na severidade final houve uma diferença de $35 \%$, porém não foi significativa estatisticamente (Tabela 1).

No ano de 2013 a ocorrência do míldio causado por $P$. destructor foi à doença que incidiu sobre a cultura. Tanto a AACPD quanto a severidade da doença foram estatisticamente diferentes, apresentando respectivamente uma diferença de $87,27 \%$ e $85 \%$ com e sem o túnel baixo (Tabela 1).

A redução da incidência de doenças em decorrência do uso da cobertura plástica tem sido destacada no cultivo de videira, onde constataram-se redução de $87 \%$ a $92 \%$ na AACPD no míldio da videira proporcionado pelo uso da cobertura plástica (8). Em cebola, Cardoso \& Costa (4), avaliando a produção de mudas de cebola em bandejas de isopor nas condições de ambiente protegido, verificaram uma incidência reduzida das doenças foliares em decorrência da diminuição do molhamento foliar. Isso é decorrente porque na produção de mudas em canteiros no sistema convencional as plantas são totalmente expostas a estresses bióticos e abióticos, sendo um sistema pouco eficiente quanto à fitossanidade, já que as plantas são vulneráveis às condições ambientais (10). Isso reflete diretamente na redução do número de fungicidas que pode ser utilizado na cultura, pois em videira constatou-se redução de $75 \%$ de aplicações para controle de doenças da parte aérea com o uso de cobertura plástica (5).

Tabela 1. Área abaixo da curva de progresso da doença (AACPD) e severidade final da queima das pontas (Botrytis squamosa) no ano 2012 e do míldio (Peronospora destructor) no ano 2013 e sua produção de massa fresca da parte aérea ( $\mathrm{g}$ ) em mudas de cebola obtidas com e sem túnel baixo. IFC, Campus Rio do Sul/SC, 2012/2013

\begin{tabular}{ccccccc}
\hline \multirow{2}{*}{ Tratamento } & \multicolumn{4}{c}{ Queima das pontas } & & Míldio \\
\cline { 2 - 7 } & AACPD & Severidade final (\%) & Massa fresca (g) & AACPD & Severidade final (\%) & Massa fresca (g) \\
\hline Coberto & $108,52 \mathrm{~b}$ & $16,91 \mathrm{~ns}$ & $83,95 \mathrm{a}$ & $30,63 \mathrm{~b}$ & $5,81 \mathrm{~b}$ & $75,51 \mathrm{a}$ \\
Descoberto & $189,99 \mathrm{a}$ & 25,92 & $36,92 \mathrm{~b}$ & $240,76 \mathrm{a}$ & $38,78 \mathrm{a}$ & $33,50 \mathrm{~b}$ \\
\hline CV $(\%)$ & 24,62 & 29,56 & 14,76 & 31,41 & 23,23 \\
\hline
\end{tabular}

Médias seguidas da mesma letra na coluna não diferem estatisticamente pelo teste $\mathrm{F}$ ao nível de 5\%. ns = não significativo pelo teste de $\mathrm{F}$ ao nível de $5 \%$ de probabilidade. 
Apesar do custo inicial do túnel, esse será viável por vários anos, já que o período de uso é em torno de 60 dias no ano, mas também no uso múltiplo do canteiro com outras culturas em sucessão amenizaria o custo, pois, aproveitaria a adubação residual e a própria cobertura para a produção de hortaliças de alto valor agregado, como alface ou morango.

O uso de túnel baixo é uma alternativa viável para aumentar o rendimento e diminuir a severidade de doenças foliares na produção de mudas de cebola.

\section{REFERÊNCIAS}

1. Boff, P. Levantamento de doenças na cultura da cebola, em Santa Catarina. Fitopatologia Brasileira, Brasília, v.21, n.1, p.110-114, 1996.

2. Boff, P.; Debarba, J.F. Tombamento e vigor de mudas de cebola em função de diferentes profundidades e densidades de semeadura. Horticultura Brasileira, Vitória da Conquista, v. 17, n.1, p.15-17, 1999.

3. Canteri, M.G.; Althaus, R.A.; Virgens Filho, J.S.; Giglioti, E.A.; Godoy, C.V. SASM - Agri: Sistema para análise e separação de médias em experimentos agrícolas pelos métodos Scoft - Knott, Tukey e Duncan. Revista Brasileira de Agrocomputação, Ponta Grossa, v.1, n.2, p.18-24, 2001.
4. Cardoso, A.I.I.; Costa, C.P. Produção de bulbinhos de cebola em bandejas de isopor. Scientia Agricola, Piracicaba, v.56, n.4, p.969-974, 1999.

5. Genta, W.; Tessmann, D.J; Roberto, S.R; Vida, J.B; Colombo, L.A.; Scapin, C.R.; Ricce, W.S.; Clovis, L.R. Manejo de míldio no cultivo protegido de videira de mesa 'BRS Clara'. Pesquisa Agropecuária Brasileira, Brasília, v.45, n.12, p.1388-1395, 2010.

6. Reghin, M.Y.; Otto, R.F.; Jacoby, C.F.S.; Olinik, J.R. Influência do tipo de bandeja na produção de mudas e no rendimento e qualidade de bulbos de cebola de diferentes cultivares em cultivo sob palhada. Ciência e Agrotecnologia, Lavras, v.30, n.1, p.58-66, 2006.

7. Sá, G.D; Reghin, M.Y. Desempenho de duas cultivares de chicória em três ambientes de cultivo. Ciência e Agrotecnologia, Lavras, v.32, n.2, p.378-384, 2008.

8. Souza, R.T.; Naves, R.L.; Velini, E.D.; Trindade, M.L.B. Controle do míldio da videira com diferentes volumes de aplicação e degradação de fungicida em cultivo protegido por cobertura plástica. EMBRAPA: Uva e Vinho: Bento Gonçalves, 2013, 8 p. Comunicado técnico 135.

9. Streck, L.; Schneider, F.M.; Buriol, G.A.; Luzza, J.; Sandri, M.A. Sistema de produção de alface em ambiente parcialmente modificado por túneis baixos. Ciência Rural, Santa Maria, v.37, n.3, p.667-675, 2007.

10. Vincenzo, M.C.V.; Tessarioli Neto, J. Onion seedling production in styrofoam trays under controlled environment, as summer-planted onions. Scientia Agricola, Piracicaba, v.60, n.1, p.65-69, 2003. 